\title{
A TRADUÇÃO DA OBSCENIDADE EM ROMEU E JULIETA ${ }^{1}$
}

\section{Elizabeth Ramos}

No Ato II, cena 2 do texto dramático de Hamlet, o leitor encontra o seguinte diálogo entre Polônio e o Príncipe Hamlet:

Polônio: [...] O que estais lendo?

Hamlet: Palavras, palavras, palavras.

Volto-me, pois, à resposta do Príncipe dinamarquês ao pai de sua amada Ofélia, para analisar o uso das palavras na construção de imagens obscenas em Romeu e Julieta (circa 1594) de William Shakespeare, peça que, segundo Stanley Wells (Wells, 2010, p. 151), começa com sexo sem amor e prossegue com amor sem sexo. Meu interesse concentra-se em observar as soluções encontradas pelos tradutores F. Carlos de Almeida Cunha Medeiros/Oscar Mendes (1969) e Barbara Heliodora (2006), na reconfiguração, em português brasileiro, dos criativos termos de espirituosa conotação sexual sob uma perspectiva transgressora.

Para sedimentar minhas reflexões, retomo não apenas o texto dramático e suas conotações obscenas. Chamo a atenção para a diversidade social da plateia inglesa, isto é, as cerca de três mil pessoas que assistiam a cada uma das encenações teatrais durante o período elizabetano, e que justificavam a necessidade de diversidade temática e estética das quase duzentas peças produzidas a cada temporada. No espaço teatral, ricos e pobres, nobres e plebeus, homens e mulheres buscavam o fascínio e a diversão, e precisavam ser correspondidos no seu anseio. De cada oito habitantes, um ia ao teatro entre duas e três vezes por semana, o que dava à plateia notável habilidade para identificar e decodificar as

\footnotetext{
${ }^{1}$ Trabalho parcialmente apresentado na IV Jornada Shakespeariana, realizada em 24-26 de outubro de 2012 na USP, em São Paulo.
} 
insinuações e indiretas nas falas das personagens. Essa sagacidade no desvendar o discurso obsceno reflete-se na expressão que se usava, a época, para expressar a relação entre o espectador e o que se apresentava no palco. Ia-se ao teatro para se "ouvir a peça", ao invés de "ver". (Kiernan, 2006, p.3) Como não havia o que hoje conhecemos como efeitos especiais, a plateia habituou-se a apurar a interpretação dos gestos, da mímica e da fala dos atores, que recriavam de forma extraordinária lugares e mundos invisíveis e desconhecidos. Além disso, no seu cotidiano, o povo estava habituado a fazer uso de uma linguagem lasciva, crua e pouco apurada, para dissimular ou refletir as agruras da vida da época - o desemprego, a fome, a violência, as doenças, a mortalidade infantil, a sujeira de uma Londres fétida.

Localizados na margem sul do Tâmisa, os prédios dos teatros misturavam-se aos prostíbulos e tavernas, numa região conhecida pela prática da indústria do sexo, o "submundo de Londres, fora da jurisdição do Prefeito e dos puritanos, um lugar onde operavam criminosos, e os condenados eram jogados em uma das suas cinco prisões" (Kiernan, 2006, p.27).

Dentro desse cenário urbano, não surpreende que a linguagem utilizada nos palcos buscasse construir correspondência com o mundo externo ao teatro.

Decorridos cinco séculos, os textos dramáticos ingleses do período renascentista ganharam mundo, exigindo inúmeras traduções que buscam também fascinar outros públicos, em outras configurações sociais. No caso específico do texto dramático de William Shakespeare e do seu uso perspicaz e malicioso do léxico na construção de imagens de conteúdo sexual obsceno, os tradutores enfrentam dificuldades por vezes inimagináveis aos olhos dos críticos e das plateias contemporâneas.

A primeira dificuldade diz respeito ao intervalo de tempo decorrido entre 1597 quando da primeira impressão gráfica da peça - e os nossos dias. Afinal, os conceitos de obscenidade são extremamente voláteis e variáveis nas diferentes geografias ao longo do tempo, de acordo com os interesses e mecanismos vigentes para seu uso. Nunca houve, de fato, critérios seguros de estabelecimento das fronteiras "entre o lícito, o ilícito e o tolerado" (Maingeneau, 2010, p.14) no universo literário. Vários termos rotulados como pornográficos em uma determinada época e lugar não mais são considerados como tal em outras épocas e lugares. Por outro lado, um termo ou frase que hoje parecem extremamente 
sutis com referência às imagens obscenas poderia ser facilmente compreendido como cru por uma plateia do século XVI.

Ademais, a semiologia construída pelo dramaturgo inglês é frequentemente dominada pelo uso de termos específicos - como nomes de frutas, por exemplo - que, não encontrando contraponto na nossa cultura, em geral, acabam impondo dificuldade à interpretação necessária ao processo tradutório da obscenidade.

As distâncias temporal e espacial impõem, no caso da discussão em pauta, pelo menos mais uma dificuldade à tradução de aspectos da linguagem conotativa sexual: ser direta, no sentido de não acrescentar filtros entre o espectador e a peça, ou o leitor e suas leituras. Cinco séculos depois da primeira encenação de Romeu e Julieta, torna-se difícil identificar até que ponto o léxico usado por William Shakespeare se adéqua ao rótulo de obsceno, dado ao fato de que a linguagem do dramaturgo pode parecer-nos, hoje, extremamente sutil em alguns pontos.

[...] Diz-se que no início do século XVII ainda vigorava uma certa franqueza. As práticas não procuravam o segredo; as palavras eram ditas sem reticência excessiva e, as coisas, sem demasiado disfarce; tinha-se com o ilícito uma tolerante familiaridade. Eram frouxos os códigos da grosseria, da obscenidade, da decência, se comparados com os do século XIX. Gestos diretos, discursos sem vergonha, transgressões visíveis, anatomias mostradas e facilmente misturadas, crianças astutas vagando, sem incômodo nem escândalo, entre os risos dos adultos: os corpos "pavoneavam". (Foucault, 2011, p. 9)

As palavras de Foucault podem ajudar-nos a compreender melhor o uso da linguagem com conteúdo obsceno-sexual em Romeu e Julieta, peça escrita no final do século XVI e, surpreendentemente, uma das mais obscenas na produção dramática shakespeariana, repleta de duplos sentidos e trocadilhos, tendo sido excluída de vários compêndios escolares, palcos e telas de cinema, ao longo do tempo. No entanto, como herdamos a tendência predominante nos séculos XVIII e XIX de suprimir ou negar obscenidade na linguagem shakespeariana, Romeu e Julieta insere-se entre os textos românticos e sentimentais na história da literatura e das artes dramáticas, levando os tradutores, muitas vezes, a ignorar ou desprezar expressões com as quais o dramaturgo constrói as chamadas imagens devassas. Naquela época, os bardólatras argumentavam que o uso de linguagem com conotação explicitamente sexual devia-se ao desejo do dramaturgo de agradar as plateias menos refinadas, justificando, portanto a necessidade de se 
eliminarem tais construções num texto que se tornara canônico. Anos mais tarde, já no século XX, Sigmund Freud, em $O$ chiste e sua relação com o inconsciente (1969, p.147), corrobora a opinião de que a história obscena estaria vinculada às camadas sociais menos privilegiadas, para intimidar a mulher. Com o passar do tempo, a obscenidade deixa de ser dirigida somente à mulher, passando a ter como alvo as plateias, que se deleitam na condição de avaliadoras da qualidade da transgressão.

Claro está, por conseguinte, que a mais famosa história de amor escrita por William Shakespeare baseia-se não apenas em aspectos românticos, mas também na sexualidade, através de sentidos duplos, trocadilhos, insinuações responsáveis pelos diálogos obscenos. É importante esclarecer, no entanto, que quando Shakespeare faz uso da palavra "sexo" o sentido diz respeito ao gênero, uma vez que o termo como sinônimo de relação sexual apareceu apenas em 1929, com o romance de D. H. Lawrence's, Lady Chatterley's Lover (Wells, 2010, p. 5).

Feitas essas considerações, creio ser importante formular a diferença entre obscenidade e pornografia, particularmente no caso das artes dramáticas, nas quais o investimento na pornografia parece-me apenas marginal. "Se quiser ser realmente pornográfico, ele [o teatro] terá de exibir atividades sexuais efetivas [...]" (Maingueneau, 2010, p. 20), o que certamente não ocorria nos palcos elizabetanos. Como o objeto do meu interesse não é a literatura pornográfica, ou mesmo a discussão sobre aspectos a ela relacionados, utilizarei ao longo do artigo o termo obscenidade para me referir ao léxico que reflete uma "maneira imemorial e universal de dizer a sexualidade" (Maingueneau, 2010, p. 25), de forma transgressora.

As análises aqui contempladas buscam, em primeiro lugar, identificar a linguagem transgressora e examinar as escolhas dos tradutores, ao se depararem com observações espirituosas, metáforas ou alusões de cunho obsceno no texto dramático de Romeu $e$ Julieta. Interessa-me, em particular, observar se os tradutores optaram por termos mais diretos, por suavizar o léxico conotativo ou por eliminá-lo totalmente.

A peça tem início com a entrada em cena dos empregados dos Capuletos - Sansão e Gregório - que estabelecem um diálogo rico em imagens obscenas, enquanto passeiam pela praça pública. 


\begin{tabular}{|c|c|c|}
\hline $\begin{array}{l}\text { William Shakespeare } \\
\text { Samson: I will show myself a } \\
\text { tyrant: when I have fought with } \\
\text { the men I will be civil with the } \\
\text { maids - I will have cut off their } \\
\text { heads. } \\
\text { Gregory: The heads of the } \\
\text { maids? } \\
\text { Samson: Ay, the heads of the } \\
\text { maids, or their maidenheads, } \\
\text { take it in what sense thou wilt. } \\
\text { Gregory: They must take it in } \\
\text { sense that feel it. } \\
\text { Samson: Me they shall feel } \\
\text { while I am able to stand, and } \\
\text { 'tis known I am a pretty piece } \\
\text { of flesh. }\end{array}$ & $\begin{array}{l}\text { Barbara Heliodora } \\
\text { Sansão: Vou bancar o tirano: } \\
\text { depois de brigar com os } \\
\text { homens, serei civilizado com } \\
\text { as donzelas, cortando-lhes as } \\
\text { cabeças. } \\
\text { Gregório: As cabeças das } \\
\text { donzelas? } \\
\text { Sansão: Cabeças ou cabaços; } \\
\text { dê o sentido que quiser. } \\
\text { Gregório: Elas terão de dar o } \\
\text { sentido que sentirem. } \\
\text { Sansão: A mim elas vão sentir } \\
\text { enquanto eu me aguentar ereto; } \\
\text { e todos me conhecem como } \\
\text { um bom pedaço de carne. }\end{array}$ & $\begin{array}{l}\text { Cunha Medeiros/Mendes } \\
\text { Sansão: [...] Mostrar-me-ei um } \\
\text { tirano! Depois que me houver } \\
\text { batido com os homens, serei } \\
\text { cruel com as mulheres. Vou } \\
\text { cortar-lhes a cabeça. } \\
\text { Gregório: As cabeças das } \\
\text { donzelas? } \\
\text { Sansão: Sim, a cabeça das } \\
\text { donzelas ou a virgindade delas. } \\
\text { Toma no sentido que quiseres. } \\
\text { Gregório: Aquelas que o } \\
\text { sentirem, o tomarão no } \\
\text { verdadeiro sentido. } \\
\text { Sansão: Elas me sentirão, } \\
\text { enquanto possa manter-me de } \\
\text { pé e é sabido que sou um belo } \\
\text { pedaço de carne! }\end{array}$ \\
\hline
\end{tabular}

Ambos os tradutores escolheram jogos de palavras bastante criativos, embora a escolha de Barbara Heliodora nos pareça mais contemporânea, quando opta pela oposição dos itens lexicais "cabeça" e "cabaço". A observação reflete, naturalmente, o hiato de tempo decorrido entre as duas traduções, com implicações significativas em termos do uso da linguagem: a de Cunha Medeiros foi publicada em 1969, e a de Barbara Heliodora, em 1991. É relevante observar, ainda, o fato de que a tradução de Cunha Medeiros está toda em prosa, enquanto a de Heliodora reproduz a combinação de Shakespeare, substituindo os pentâmetros jâmbicos por decassílabos. A escolha, evidentemente, acarreta implicações no leque de soluções tradutórias disponíveis.

No exemplo acima, é interessante observar que as duas traduções brincam com o termo sentido, que se desloca polissemicamente entre significado e sensação. Cunha Medeiros e Mendes optam pela sutileza, quando, ao aludir à sustentação da ereção, referemse à capacidade de Sansão de manter-se de pé.

No exemplo seguinte, ainda no Ato I, cena 1, o leitor se depara com uma situação engraçada em que, por meio do uso criativo do léxico, a Senhora Capuleto faz insinuações sobre o desempenho sexual do marido, manifestando a sua frustração ao opor o termo espada - signo de virilidade - ao item lexical muleta. 


\begin{tabular}{|c|c|c|}
\hline William Shakespeare & Barbara Heliodora & Cunha Medeiros/Mendes \\
\hline Capulet: What noise is this? & Capuleto: Que barulho é esse? & Capuleto: Que barulho é este? \\
\hline Give me my long sword, ho! & Dêem-me a espada! & $\begin{array}{l}\text { Dêem-me minha espada de } \\
\text { combate! Vamos! }\end{array}$ \\
\hline $\begin{array}{l}\text { Capulet's Wife: A crutch, a } \\
\text { crutch - why call you for a } \\
\text { sword? }\end{array}$ & $\begin{array}{l}\text { Sra. Capuleto: Uma muleta! } \\
\text { Por que uma espada? }\end{array}$ & $\begin{array}{l}\text { Sra. Capuleto: Uma muleta! } \\
\text { Uma muleta! Por que pedir uma } \\
\text { espada? }\end{array}$ \\
\hline $\begin{array}{l}\text { Capulet: My sword, I say. Old } \\
\text { Montague is come, } \\
\text { And flourishes his blade in } \\
\text { spite of me. }\end{array}$ & $\begin{array}{l}\text { Capuleto: Minha espada, eu } \\
\text { disse! Lá vem Montéquio } \\
\text { brandindo a lâmina pra me } \\
\text { insultar. }\end{array}$ & $\begin{array}{l}\text { Capuleto: Minha espada, estou } \\
\text { dizendo! Chega o velho } \\
\text { Montecchio e brande sua } \\
\text { lâmina, a despeito meu! }\end{array}$ \\
\hline
\end{tabular}

Ambos os tradutores mantêm o jogo entre as palavras espada e muleta, deixando ao leitor a construção da duplicidade de sentidos.

No Ato I, cena 1, um diálogo entre Romeu e Benvólio alude à mitologia para construir a imagem do falo através da flecha de Cupido.

\begin{tabular}{|c|c|c|}
\hline William Shakespeare & Barbara Heliodora & Cunha Medeiros/Mendes \\
\hline $\begin{array}{l}\text { Romeo: Well, in that hit you } \\
\text { miss. She'll not be hit } \\
\text { With Cupid's arrow; she hath } \\
\text { Dian's wit, } \\
\text { And, in strong proof of chastity } \\
\text { will armed [...] }\end{array}$ & $\begin{array}{l}\text { Romeu: Errou; ela não me } \\
\text { deixa eu acertar } \\
\text { Co’a flecha de Cupido. É } \\
\text { como Diana, } \\
\text { Armada fortemente em } \\
\text { castidade }[. . .]\end{array}$ & $\begin{array}{l}\text { Romeu: Bem, desta vez não } \\
\text { atingiste o alvo! Ela não se } \\
\text { deixa atingir pela seta de } \\
\text { Cupido. Possui a sabedoria de } \\
\text { Diana e, protegida por uma } \\
\text { castidade bem armada [...] }\end{array}$ \\
\hline
\end{tabular}

O fragmento de Cunha Medeiros e Mendes, acima, parece demonstrar maior carga de explicitação erótica, ao complementar de forma direta - "ela não se deixa atingir pela seta de Cupido" - com a frase - "protegida por uma castidade bem armada".

A busca por trechos que possam fornecer material para análise da tradução do léxico com conotação obscena cai, em particular, sobre dois personagens - Mercúcio e a Ama - que, com vivacidade, exuberância e ironia verbal, não apenas roubam a cena, mas constroem uma linguagem rica em representações transgressoras.

Na Cena 3 do Ato I, temos exemplos desse tipo de léxico, quando a Ama conversa com a Senhora Capuleto e Julieta, recordando a época em que deixou de amamentar a menina. 


\begin{tabular}{|c|c|c|}
\hline $\begin{array}{l}\text { William Shakespeare } \\
\text { Nurse: [...] She could have run } \\
\text { and waddled all about, } \\
\text { For even the day before, she } \\
\text { broke her brow; } \\
\text { And then my husband - God } \\
\text { be with his soul, } \\
\text { A was a merry man! - took up } \\
\text { the child. } \\
\text { 'Yea', quoth he, 'dost thou fall } \\
\text { upon thy face? } \\
\text { Thou will fall backward when } \\
\text { thou hast more wit, } \\
\text { Wilt thou not, Jule?', and by } \\
\text { my halidom, } \\
\text { The pretty wretch left crying, } \\
\text { and said 'Ay'. [...] } \\
\text { Lady C. Enough of this. I pray } \\
\text { thee, hold thy peace. } \\
\text { Nurse: Yes, madam. Yet I } \\
\text { cannot choose but laugh } \\
\text { To think it should leave crying, } \\
\text { and say 'Ay': } \\
\text { And yet, I warrant, it had upon } \\
\text { its brow } \\
\text { A bump as big as a young } \\
\text { cock'rel's stone; } \\
\text { A perilous knock, and it cried } \\
\text { bitterly. } \\
\text { 'Yea', quoth my husband, } \\
\text { fall'st upon thy face? } \\
\text { Thou wilt fall bakward when } \\
\text { thou com'st to age, } \\
\text { Wilt thou not, Jule?' It stinted, } \\
\text { and said 'Ay'. }\end{array}$ & $\begin{array}{l}\text { Barbara Heliodora } \\
\text { Ama: [...] Já andava e corria } \\
\text { por aí, } \\
\text { Pois nesse dia ela bateu com a } \\
\text { cabeça; } \\
\text { E então meu marido - Deus o } \\
\text { tenha - } \\
\text { Que era muito alegre - } \\
\text { levantou-a, } \\
\text { Dizendo - "Mas se cai assim, } \\
\text { de cara? } \\
\text { Quando souber das coisas, cai } \\
\text { de costas, } \\
\text { Não é, Julinha?" E por tudo } \\
\text { que é sagrado, } \\
\text { A boba ficou quieta e disse } \\
\text { "É.” [...] } \\
\text { Sra. Capuleto: Agora, chega. } \\
\text { Por favor, silêncio. } \\
\text { Ama: Sim, senhora, mas é } \\
\text { mesmo de rir } \\
\text { Ela, sem uma lágrima, } \\
\text { responder "É". } \\
\text { E eu garanto que, bem aqui na } \\
\text { testa, } \\
\text { Tinha um inchaço que até } \\
\text { parecia } \\
\text { culhão de galo, e que doía } \\
\text { muito. }\end{array}$ & $\begin{array}{l}\text { Cunha Medeiros/Mendes } \\
\text { Ama: [...] podia já correr e } \\
\text { tropeçar por todas as partes, } \\
\text { pois precisamente, no dia } \\
\text { anterior, se ferira na cabeça. } \\
\text { E então, meu marido (que na } \\
\text { glória esteja!), que era homem } \\
\text { jovial, levantou a pequena e lhe } \\
\text { disse: "Então, caíste de bruços? } \\
\text { Quando tiveres mais juízo, } \\
\text { cairás de costas. Não é verdade, } \\
\text { Júlia?" E por Nossa Senhora, a } \\
\text { linda pequena deixou de chorar } \\
\text { imediatamente e exclamou: } \\
\text { "Sim". [...] } \\
\text { Sra. Capuleto: Chega disso. } \\
\text { Por favor, cala-te. } \\
\text { Ama: Sim, senhora; mas não } \\
\text { posso deixar de rir pensando } \\
\text { que parou de chorar e disse } \\
\text { "Sim", e que posso garantir- } \\
\text { vos, tinha na testa um galo tão } \\
\text { grande quanto um ovo de } \\
\text { galinha; uma pancada perigosa; } \\
\text { e ela chorava desoladamente. }\end{array}$ \\
\hline
\end{tabular}

Existe uma clara diferença entre o léxico escolhido pelos dois tradutores. A expressão pouco usual para se referir a um ferimento na testa de numa criança de dois anos - young cock'rel's stone - é abrandada por Cunha Medeiros e Mendes com a tradução ovo de galinha, termo que remete à palavra galo, normalmente utilizada para se referir àquele tipo de contusão. Se por um lado, Nunes e Mendes optam por filtrar as indiscrições da Ama, Heliodora prefere manter a transgressão ao escolher o termo culhão de galo. 
Na cena 1, do Ato II, Mercúcio, personagem obcecado por obscenidade, dá ao leitor talvez o mais extraordinário exemplo da linguagem objeto das nossas observações, no seguinte trecho.

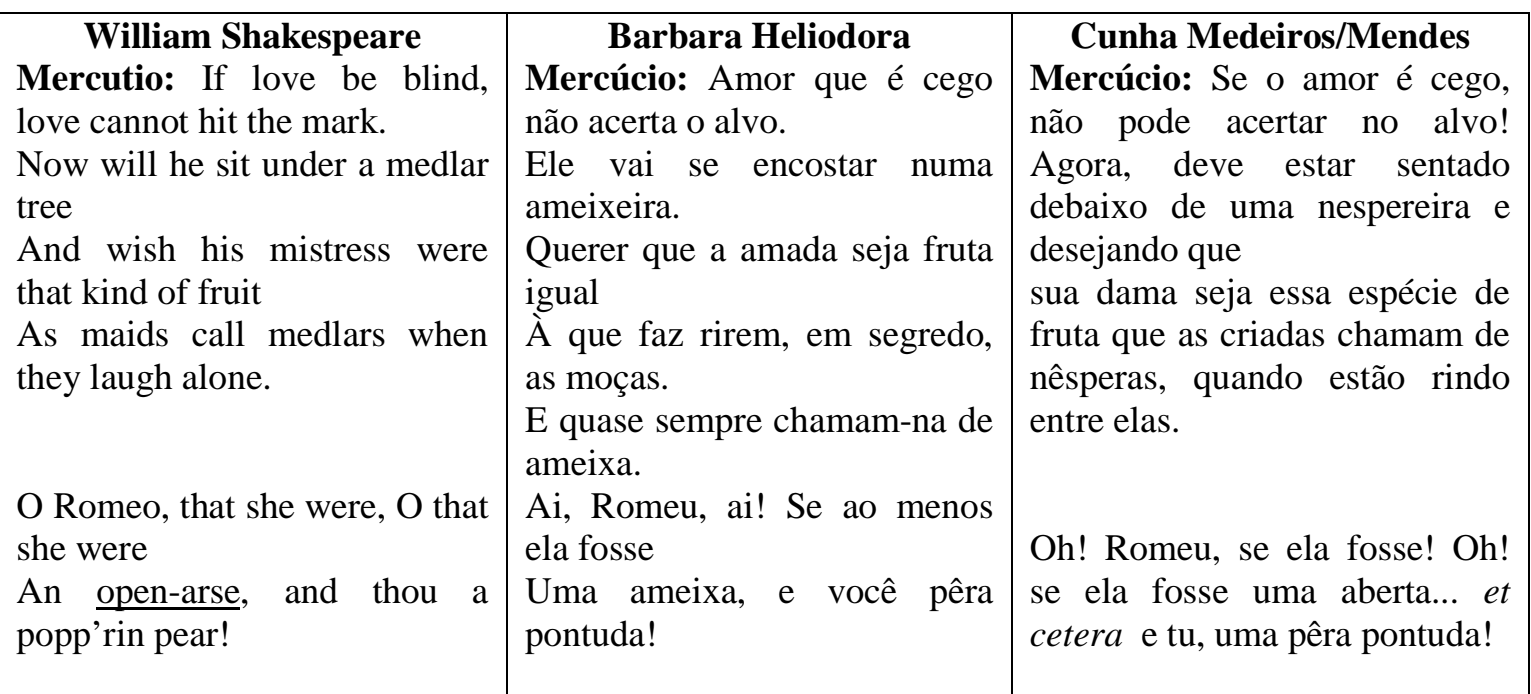

O leitor do texto dramático em inglês encontra a expressão an open-arse (uma bunda arreganhada), que faz emergir o que havia sido apenas sugerido metaforicamente através do uso do termo dialetal medlar, fruta que, quando partida ao meio se assemelha à genitália feminina. Em termos linguísticos, medlar deriva do verbo meddle, que pode ser sinônimo de 'introduzir à força', 'meter', numa referência óbvia ao ato sexual. Nenhum dos tradutores traz ao seu texto o termo cru, preferindo manter a insinuação. Heliodora preserva a metáfora e a tradução de Cunha Medeiros/Mendes escolhe a estratégia usada em meados do século XX, de omitir o aspecto transgressor do item lexical, substituindo-o por et cetera. A opção é natural, visto que a tradução foi produzida em meados dos anos 1960 e publicada em 1969. No entanto, estes tradutores inserem duas notas de rodapé para explicarem os termos em inglês medlars: "tem quase a mesma pronúncia do que meddlerarse, ou seja, para sugerir o orifício retal, daí a causa do riso das criadas"; e poperin pear: "uma pera oriunda de Poperinghe (na Flandres) que tinha uma forma pontuda. Serve para continuar o sentido obsceno dos comentários de Mercúcio” (Shakespeare, 1995, p. 353).

Observando os exemplos selecionados, constatamos que grande parte do léxico com conotação obscena é permeado de humor, característica que acaba sendo sufocada pela 
paixão entre os amantes de Verona. O amor em Romeu e Julieta é, portanto um contraponto dos jogos de obscenidade.

É interessante observar, todavia, que William Shakespeare constrói esse contraponto, inovando, trazendo ao palco uma linguagem particular para cada personagem dentro de uma dada situação. A identificação de um trocadilho obsceno, muitas vezes, depende de quem fala e de quem é dirigida a fala, além do contexto e do tom da cena, evidentemente. No caso de Romeu e Julieta, um trocadilho vindo de Mercúcio ou da Ama pode ser bem menos sutil do que aquele que é emitido, por exemplo, pela Senhora Capuleto. Talvez advenha desse fato a riqueza de vocabulário criado e usado pelo dramaturgo, uma vez que sua obra dramática traz a público uma galeria de diferentes personagens. Não raro, ele emprega o léxico existente de modo inovador, criatividade essa estimulada pelo período de grandes transformações da língua inglesa no século XVI. De acordo com Barbara Heliodora, "toda ação dramática e todo personagem que atuava era não mais que produto da capacidade do autor de manipular palavras" (Heliodora, 2004, p. 261).

\section{Amor e obscenidade}

Com a morte de Mercúcio, para quem o amor não passava do encaixe de uma pera pontuda numa nêspera, opera-se uma transformação radical na peça. O léxico passa a se concentrar na construção do amor entre Romeu — um joguete do destino — e Julieta relicário de um amor sem fim. Isso não significa, no entanto, que a linguagem de amor não seja permeada por erotismo, como que para temperar o amor romântico.

Em Romeu e Julieta, quando o protagonista vê aquela que seria sua amada e por ela se apaixona à primeira vista, no baile dos Capuleto (Ato I, cena 5), inaugura a religião do amor através de palavras como abençoar e jurar, não sem antes antecedê-las de uma metáfora extremamente erótica, como se pode observar no recorte abaixo:

\begin{tabular}{|l|l|l|}
$\begin{array}{l}\text { William Shakespeare } \\
\text { meo: O, she doth teach the } \\
\text { ches to burn bright! }\end{array}$ & $\begin{array}{l}\text { Barbara Heliodora } \\
\text { Romeu: Ela é que ensina as as } \\
\text { tochas a brilhar, }\end{array}$ & $\begin{array}{l}\text { Cunha Medeiros/Mendes } \\
\text { Romeu: Oh! ela deve ensinar } \\
\text { às tochas a brilharem } \\
\text { esplendidamente. }\end{array}$ \\
\hline
\end{tabular}

Em ambas as traduções, a tocha, um possível símbolo fálico, não está associada ao verbo arder, como acontece no texto de partida, a fim de estimular a alusão à ereção, preservando a obscenidade velada. 
E no Ato I, cena 5, a louvação ao amor sagrado, mesclando palavras como sacrário, santo peregrino, lábios e beijo, é temperada com evocações de erotismo por meio de imagens construídas com os movimentos das mãos.

\begin{tabular}{|c|c|c|}
\hline $\begin{array}{l}\text { William Shakespeare } \\
\text { Romeo: If I profane with my } \\
\text { unworthiest hand } \\
\text { This holy shrine, the gentler sin } \\
\text { is this: } \\
\text { My lips, two blushing pilgrims, } \\
\text { ready stand } \\
\text { To smooth that rough touch } \\
\text { with a tender kiss. } \\
\text { Juliet: Good pilgrim, you do } \\
\text { wrong, your hand too much. } \\
\text { Which mannerly devotion } \\
\text { shows in this. } \\
\text { For saints have hands that } \\
\text { pilgrims' hands do touch, } \\
\text { And palm to palm is holy } \\
\text { palmers' kiss. } \\
\text { Romeo: Have not saints lips, } \\
\text { and holy palmers too? } \\
\text { Juliet: Ay, pilgrim, lips that } \\
\text { they must use in prayer. } \\
\text { Romeo: O, then, dear saint, let } \\
\text { lips do what hands do: } \\
\text { They pray, grant thou, lest faith } \\
\text { turn to despair. } \\
\text { Juliet: Saints do not move, } \\
\text { though grant for prayers' sake. } \\
\text { Romeo: Then move not while } \\
\text { my prayer's effect I take. [... } \\
\text { Thus from my lips, by thine my } \\
\text { sin is purged. } \\
\text { Juliet: Then have my lips the } \\
\text { sin that they have took. } \\
\text { Romeo: Sin from my lips? O } \\
\text { trespass sweetly urged! Give } \\
\text { me my sin again. } \\
\text { Juliet: You kiss by th' book. }\end{array}$ & 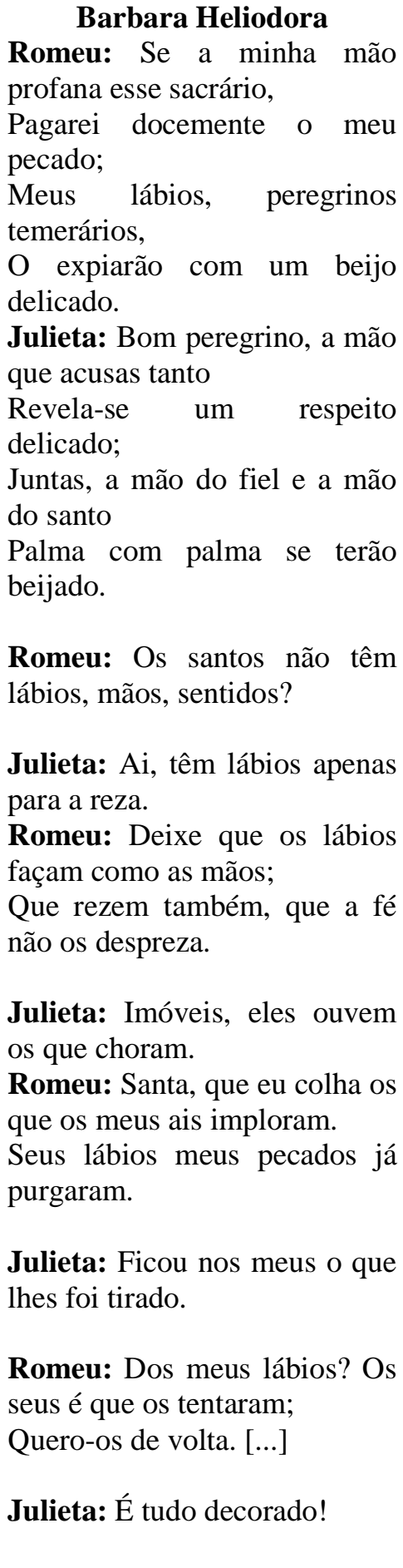 & $\begin{array}{l}\text { Cunha Medeiros/Mendes } \\
\text { Romeu: Se profano com minha } \\
\text { mão por demais indigna esse } \\
\text { santo relicário, a gentil } \\
\text { expiação é esta: meus lábios, } \\
\text { dois ruborizados peregrinos, } \\
\text { estão prontos a suavizar com } \\
\text { um terno beijo tão rude contato. } \\
\text { Julieta: Bondoso peregrino, } \\
\text { injusto até o excesso sois com } \\
\text { vossa mão, que mostrou } \\
\text { devoção cortês; pois as santas } \\
\text { têm mãos que são tocadas pelas } \\
\text { dos peregrinos e enlaçar palma } \\
\text { com palma é o ósculo dos } \\
\text { piedosos portadores de palmas. } \\
\text { Romeu: Não têm lábios as } \\
\text { santas e lábios também os } \\
\text { piedosos peregrinos? } \\
\text { Julieta: Sim, peregrino, lábios } \\
\text { que devem usar na oração. } \\
\text { Romeu: Oh! Então santa } \\
\text { adorada, deixai que os lábios } \\
\text { façam o que as mãos fazem. } \\
\text { Elas oram, accedei para que a fé } \\
\text { não se mude em desespero! } \\
\text { Julieta: As santas são imóveis } \\
\text { mesmo atendendo às orações. } \\
\text { Romeu: Então não vos movais, } \\
\text { enquanto recolho o fruto de } \\
\text { minhas preces. Assim, mediante } \\
\text { vossos lábios ficam os meus } \\
\text { livres de pecado. } \\
\text { Julieta: Deste modo passou } \\
\text { para os meus lábios o pecado } \\
\text { que os vossos contraíram. } \\
\text { Romeu: Pecado de meus } \\
\text { lábios? } \text { Oh! } \\
\text { deliciosamente censurada ao } \\
\text { pecador! Devolvei então meu } \\
\text { pecado. } \\
\text { Julieta: Beijais segundo as } \\
\text { maneiras elegantes. }\end{array}$ \\
\hline
\end{tabular}


No trecho acima, volúpia e religiosidade, ao invés de se contraporem, enriquecem o erotismo, dando sabor ao diálogo. Nesse sentido, não creio que a última fala de Julieta no fragmento das duas traduções deixe transparecer o jogo estabelecido entre os dois personagens. A opção de Cunha Medeiros e Mendes apaga qualquer possibilidade de erotismo, e a de Heliodora torna incompreensível a malícia da resposta de Julieta.

Depois de examinar alguns fragmentos do universo lexical de Romeu e Julieta, devo respeitosamente discordar do eminente acadêmico shakespeariano, Professor Stanley Wells, quando afirma que a peça começa com sexo sem amor, e prossegue com amor sem sexo. $\mathrm{O}$ que minhas observações indicam é que a peça tem início com itens lexicais com carga semântica de obscenidade permeada pelo manto da sexualidade, prossegue com imagens eróticas permeadas do manto da sacralização, e se encerra, no Ato $\mathrm{V}$, cena 3, com uma representação fálica merecedora de atenção. Afinal, Julieta se mata com a adaga de Romeu, pedindo que ela se enferruje dentro de si.

Todavia, a sexualidade humana, na sua condição de construto da nossa imaginação, transforma-se ao longo do tempo, assumindo caráter multiforme sob as variáveis pressões culturais.

Em Romeu e Julieta, a grande tragédia é a impossibilidade de se atingir o amor, seja ele sagrado ou erótico. Somente na morte os amantes de Verona se unirão, e como que para marcar o culto ao amor ideal, o dramaturgo nunca mais escreveu uma tragédia lírica, depois de Romeu e Julieta.

Provavelmente, a crença de que o casal romântico tenha realmente existido se alimenta do desejo de que seu amor pudesse ter suplantado a tragédia. Seu sofrimento os transforma em oráculos, santificando-os, neutralizando tanto o universo erótico, quanto o obsceno que os precede, deslocando-os da ficção para o plano real. O culto do amor ideal, construído através de palavras, palavras, palavras, tão distante das experiências afetivas da contemporaneidade, nos estimula a perpetuar o mito e configura a única possibilidade de continuar uma história interrompida.

\section{Referências}

GARBER, Marjorie. Shakespeare after all. New York: Anchor Books, 2004. 
FOUCAULT, Michel. História da sexualidade, vol. 1: a vontade de saber. Trad.: Maria Thereza da Costa Albuquerque e J.A. Guilhon Albuquerque. Rio de Janeiro: Graal, 2011.

FREUD, Sigmund. Le mot d'esprit et ses rapports avec l'inconscient. Paris: Gallimard, 1969.

HELIODORA, Barbara. Falando de Shakespeare. São Paulo: Perspectiva, 2004.

KIERNAN, Pauline. Filthy Shakespeare: Shakespeare's most outrageous sexual puns. New York: Penguin,2006

MAINGUENEAU, Dominique. O discurso pornográfico. Trad. Marcos Marcionilo. São Paulo: Parábola, 2010.

SHAKESPEARE, William. Romeu e Julieta. Trad. F. Carlos de Almeida Cunha Medeiros e Oscar Mendes. Rio de Janeiro: Nova Aguilar, 1995.

SHAKESPEARE, William. Teatro completo: tragédias e comédias sombrias. Trad. Barbara Heliodora. Rio de Janeiro: Nova Aguilar, 2006.

WELLS, Stanley. Shakespeare, Sex \& Love. New York: Oxford University Press, 2010.

WELLS, Stanley; TAYLOR, Gary (Eds.). The most excellent and lametable tragedy of Romeo and Juliet. In: The Oxford Shakespeare: the complete works. 2nd. Edition. Oxford: Clarendon Press, 2005. 